\title{
APPLICATION OF ANALYTICAL SOLUTIONS FOR BENDING BEAMS IN THE METHOD OF MOVEMENT
}

\author{
Vladimir Karpov, Evgeny Kobelev*, Aleksandr Panin \\ Saint Petersburg State University of Architecture and Civil Engineering \\ Vtoraja Krasnoarmeyskaya st., 4, Saint Petersburg, Russia \\ *Corresponding author: evgeny.kobelev@gmail.com
}

\begin{abstract}
Introduction: Usually, to analyze statically indeterminate rod systems, the classical displacement method and preprepared tables for two types of rods of the main system are used. A mathematically correct representation of local loads with the use of generalized functions makes it possible to find an accurate solution of the differential equation for the equilibrium of a beam exposed to an arbitrary transverse load. Purpose of the study: We aimed to obtain analytical expressions for functions of deflection, rotation angles, transverse forces, and bending moments depending on four types of local loads for beams with different boundary conditions, so as to apply accurate solutions in the displacement method. Methods: We propose an analytical form of the displacement method to analyze rod structural models. For beams exposed to different types of transverse load (uniformly distributed force, concentrated force, or a couple of forces), accurate analytical solutions were obtained for functions of deflection, bending moments, and transverse forces at different types of beam ends' restraint. This is possible due to the fact that concentrated load and load in the form of the moment of force can be specified by using unit column functions. By transforming Mohr's integrals, using integration by parts, we show that the system of canonical equations of the displacement method was obtained based on the Lagrange principle. Results: Based on the analysis of a statically indeterminate frame, the effectiveness of the proposed analytical method is shown as compared with the classical displacement method.
\end{abstract}

\section{Keywords}

Rod systems, displacement method, beam bending equation, Mohr's integral, mathematical model, work of internal forces, work of external forces, Lagrange principle.

\section{Introduction}

Rod systems (beams, frames, trusses, combined structures) are widely used in the construction of various structures (Babanov, 2011; Ignatyev, 1979; Leontyev et al., 1996). To perform stress-strain analysis of such structures, the displacement method is usually used (Ilin et al., 2005; Maslennikov, 1987; Maslennikov et al., 2020).

Currently, almost all structural calculations are performed with the use of computer technologies, which makes it possible to automate the process and ensure a quite high accuracy of the calculations (Akimov and Mozgaleva, 2014; Karpov, 2006, 2010, 2011; Kobelev, 2018).

It is not difficult to obtain an accurate solution of the differential equation for the equilibrium of a beam exposed to distributed load (Korn and Korn, 1974; Smirnov, 1967). However, obtaining an accurate solution for beams exposed to local loads mentioned above, described by delta functions, presents particular mathematical difficulties (Belostochny, 1999; Korneyev, 2011; Mikhailov, 1980). When a concentrated load is described by delta functions, it means that the load is applied to the point, and that is impossible in real practice. In the course of structural calculations for structures having various irregularities or exposed to local loads, the mathematical apparatus of the theory of generalized functions is widely used (Alyukov, 2011, 2012; Belostochny, 1999; Ilin et al., 2005; Kobelev, 2018; Kobelev and Lukashevich, 2020a, 2020b; Mikhailov, 1980; Mikhailov et al., 1990). To specify correctly the location of stiffeners reinforcing a shell, Karpov (Ilin et al., 2005) introduced special unit column functions equal to the difference between two unit functions and showed how to describe local loads applied to a small area, by using those functions. In this case, finding an accurate solution of the equation for the equilibrium of a beam exposed to local loads does not present any challenges (Belostochny, 1999; Korneyev, 2011; Mikhailov et al., 1990).

Analytical displacement method

Let us examine in detail the essence of the displacement method used to analyze statically indeterminate frames (Babanov, 2011; Ilin et al., 2005; Maslennikov, 1987; Maslennikov et al., 2020). In the analysis of frame systems, to obtain the main system of the displacement method, the following additional connections are introduced: angular connections preventing the rotation of joints in areas 
with no full joints, and linear connections preventing linear displacements.

After that, in the main system, unit generalized displacements (angular or linear) are specified in the direction of the introduced connections, and then, in sequence, reactions in these connections from the displacements and external load (force factors) are determined based on conformity of the main system to the specified one.

If we denote these reactions by $r_{k j}$, and unknown generalized displacements by $Z_{j}$. then overall reactions in the $j^{\text {th }}$ introduced connection in the system with $n$ unknown quantities will be equal to

$\sum_{j=1}^{n} r_{k j} Z_{j}+r_{k F}$, where $r_{k F}$ is the reaction in the $k^{t h}$ connection from the external load.

In the displacement method, the sum of reactions in the additional connections from the displacement of these connections and the external load is equal to zero, i.e.:

$$
\sum_{j=1}^{n} r_{k j} Z_{j}+r_{k F}=0 .
$$

Here, $\sum_{j=1}^{n} r_{k j} Z_{j}$ is the sum of the works of internal forces on virtual displacements; $r_{k F}$ is the sum of the works of external forces on virtual displacements.

Since reactions in additional connections act in the direction of the specified unit displacements, then the work of internal forces on these displacements is positive, and the work of external forces on virtual displacements, in the direction of additional connections preventing the displacement of joints of the main system, is negative. Therefore, the main system of the displacement method is based on the following: in equilibrium, the work of the rod system's internal forces on virtual displacements is equal to the work of external forces on virtual displacements, i.e. the displacement method uses the same idea as the Lagrange principle of virtual displacements.

The main system of the displacement method consists of individual rods, having uniform crosssection, of two types: rigid support - rigid support and rigid support - joint.

These rods are statically indeterminate beams, analyzed in structural mechanics by using the force method at various transverse loads, with their ends analyzed in terms of unit displacements. That is why, when performing calculations with the displacement method, pre-prepared tables are used (Maslennikov, 1987; Maslennikov et al., 2020).

However, to determine the stress-strain state of statically indeterminate beams, it is possible to find an analytical solution to the problem by integrating the differential equation of the deflection curve of the beam, using not only equilibrium equations (static relations) but geometric relations (kinematic relations) and boundary conditions as well.

Let us consider the work of various force factors on corresponding displacements. If a force factor is transverse load $q(x)$, which may be represented by distributed load, concentrated force, or the moment of a couple of forces, it does work on displacements $w(x)$, i.e. the work of the load is equal to $q(x) w(x)$.

If a force factor is bending moment $M_{x}=E J_{x} \chi_{1}(x)$, then it does work on displacement $\chi_{1}=-w^{\prime \prime}(x)$, which is a function of the curvature of the elastic line of the beam, i.e. the work of the moment is equal to $M_{\chi} \chi_{I}(x)$.

If a force factor is transverse force $Q_{x}$, then it does work on displacement, which is the angle of crosssection displacement that, due to its smallness, is replaced by tangent, i.e. the work of the transverse load is equal to $Q_{x} w^{\prime}(x)$.

It would be logical to think that the work of the force on some displacement is always positive. However, in structural mechanics, it is believed that it can be negative if the direction of the force does not coincide with the direction of virtual displacements. Therefore, Eq. (1) takes the plus sign.

In the classical displacement method, the coefficients of the unknown quantities and the free terms of the system of canonical equations are determined based on the equilibrium of the cutoff parts of the main system, containing additional angular and linear connections. If we use the theorem of reciprocal reactions and displacements (Babanov, 2011; Maslennikov, 1987), then the coefficients of the unknown quantities in Eq. (1) can be determined by Mohr's equation:

$$
r_{k j}=\sum_{s=1}^{m} \int_{0}^{L_{s}} \frac{M_{k}^{0} M_{j}^{0}}{E J_{s}} d x,
$$

where $m$ is the number of integration sections along the entire frame for a rod with length $L_{s}$, with constant stiffness $E J ; M_{k}^{0}$ is the bending moment in the main system of the displacement method at the section $\left[0, L_{s}\right]$ from the unit displacement of the $k^{\text {th }}$ introduced connection; $M_{j}^{0}$ is the bending moment in the main system of the displacement method at the section $\left[0, L_{s}\right]$ from the unit displacement of the $j^{\text {th }}$ introduced connection. Here, $M_{j}^{0}=-E J_{j} \varphi_{j}^{\prime \prime}(x)$, $M_{k}^{0}=-E J_{k} \varphi^{\prime \prime}(x)$. Therefore:

$$
w_{j}^{\prime \prime}(x)=Z_{j} \varphi_{j}^{\prime \prime}(x), w_{k}^{\prime \prime}(x)=Z_{k} \varphi_{k}^{\prime \prime}(x) \text {. }
$$

The free terms of the system of canonical equations of the displacement method are also determined by Mohr's equation:

$$
\begin{aligned}
& r_{k F}=-\sum_{s=1}^{m} \int_{0}^{L_{s}} \frac{M_{k}^{0} M_{F}^{0}}{E J_{s}} d x= \\
& \sum_{s=1}^{m} \int_{0}^{L_{s}} \varphi_{k}^{\prime \prime}(x) M_{F}^{0} d x,
\end{aligned}
$$


where $M_{F}^{0}$ is the bending moment in the main system of the displacement method at the section $\left[0, L_{s}\right]$ from the specified load.

By substituting the moments in Eq. (2), we obtain the following:

$$
r_{k j}=r_{j k}=\sum_{s=1}^{m} \int_{0}^{L_{s}} E J_{s} \varphi_{k}^{\prime \prime}(x) \varphi_{j}^{\prime \prime}(x) d x,
$$

which is the work of internal forces from the unit displacements in the direction of additional connections. Based on the theorem of reciprocal virtual works, $\varphi_{k}^{\prime \prime}(x)=\varphi_{j}^{\prime \prime}(x)$. Then:

$$
r_{k j} Z_{j}=\sum_{s=1}^{m} \int_{0}^{L_{s}} E J_{s} \phi_{k}^{\prime \prime}(x) \phi_{j}^{\prime \prime}(x) Z_{j} d x=\frac{\partial \prod}{\partial Z_{j}}
$$

where

$$
\begin{aligned}
& \Pi=\frac{1}{2} \int_{0}^{L_{s}} M_{x} C_{1} d x= \\
& \frac{1}{2} \int_{0}^{L_{s}} E J_{j} Z_{j} \varphi_{j}^{\prime \prime}(x) \varphi_{j}^{\prime \prime}(x) Z_{j} d x .
\end{aligned}
$$

Thus, $\sum_{j=1}^{n} r_{k j} Z_{j}$ is the sum of the works of internal forces on virtual displacements.

By transforming the integral

$$
\int_{0}^{L_{s}} \varphi_{j}^{\prime \prime}(x) M_{F}^{0} d x
$$

with the double integration by parts, we obtain

$$
\int_{0}^{L_{s}} \frac{d^{2} M_{F}^{0}}{d x^{2}} \cdot \varphi_{j}(x) d x . \quad \text { Since, } \quad \frac{d^{2} M_{F}^{0}}{d x^{2}}=-q,
$$

then:

$$
\int_{0}^{L_{s}} \varphi_{j}^{\prime \prime}(x) M_{F}^{0} d x=-\int_{0}^{L_{s}} q \varphi_{j}(x) d x
$$

Therefore:

$$
r_{k F}=\frac{\partial}{\partial Z_{j}} \sum_{s=1}^{m} \int_{0}^{L_{s}}\left[-q Z_{j} \phi_{j}(x)\right] d x=-\sum_{s=1}^{m} \int_{0}^{L_{s}} q \phi_{j}(x) d x
$$

which is the work of external forces on finite displacements.

Thus, the system of canonical equations of the displacement method (mathematical model for the deformation of rod systems) is obtained under the following condition: in equilibrium, the work of the rod system's internal forces on finite displacements is equal to the work of external forces on finite displacements. The same principle of developing a mathematical model for the deformation of rod systems is applied when the force method is used.

In the classical form of the displacement method for the formation of a system of canonical equations, it is necessary to construct in the main system, using corresponding tables, diagrams of bending moments from the sequentially specified unit displacements in the direction of additional connections $M_{i}^{0}$, where $i=1,2, \ldots . n$, and a diagram of bending moments $M_{F}^{0}$ from the external transverse load specified in a particular way. For instance, if the concentrated load is described by delta functions, then the function of bending moments $M(x)=-E J w^{\prime \prime}(x)$ contains points where the smoothness of the function is lost and sometimes breaks of continuity occur upon differentiation. If the function $w^{\prime \prime}(x)$ is characterized by discontinuity, then $w^{\prime \prime \prime}(x)$ does not exist, and the function $w(x)$ does not satisfy the equation for the equilibrium of a beam in bending $E J w^{I V}=q$. The diagrams mentioned are constructed for a beam fixed at the ends in a particular way.

In the course of the study, for different types of fixing the ends of a beam exposed to transverse load (uniformly distributed force, concentrated force, or the moment of a couple of forces), accurate analytical solutions were obtained for the function of deflection $w(x)$. This is possible due to the fact that concentrated load and load in the form of the moment of force can be specified by using unit column functions. In this case, by successive integration of the equation $E J w^{I V}=q$, it is possible to find deflection in the form of the continuous differentiable function of deflection $w(x)$, having derivatives $w^{\prime}(x), w^{\prime \prime}(x), w^{\prime \prime \prime}(x)$, and $w^{I V}(x)$ Besides, to determine the coefficients of the unknown quantities $r_{k j}$ and the free terms $r_{k F}$ of the system of canonical equations of the displacement method, there is no need to construct diagrams of bending moments $M^{0}$ and $M_{F}^{0}$ since, due to the obtained analytical expressions for $w(x)$ and $w^{\prime \prime}(x)$, the moments indicated can also be specified in the form of analytical functions considering the characteristics of the applied load.

The proposed analytical method not only simplifies the analysis of rod systems but facilitates computing programming significantly.

Let us find an analytical expression for deflection $w(x)$ bending moment $M_{x}$, and transverse force $Q_{x}$ for a beam with span $L_{s}$ under the following types of transverse load $q$ :

1. Uniformly distributed along the entire length of the beam $[0, L]$;

2. Uniformly distributed along a part of the beam $\left[x_{1}, x_{2}\right]$;

3. Concentrated, applied to some point $a_{1}$;

4. Moment of a couple of forces.

We consider two types of fixing the beam ends: rigid support at $x=0$ and $x=L$; rigid support at $x=0$ and hinged support at $x=L_{s}$. The $w(x), M_{x}$, and $Q_{x}$ expressions are determined at the unit value of the load and the arbitrary value of $E I$, where $M_{x}=-E I w^{\prime \prime}(x), Q_{x}=-E I w^{\prime \prime \prime}$.

$$
\text { If } I=\frac{h^{3}}{12} b \text {, where } b \text { is the width of }
$$


the beam, then $q\left(\frac{\mathrm{kN}}{\mathrm{m}}\right)$ is obtained by multiplying the load $q_{1} \cdot b\left(\frac{\mathrm{kN}}{\mathrm{m}^{2}} \cdot \mathrm{m}\right)$.

Let us find an accurate solution to the equation for the equilibrium of the beam:

$$
w^{\mathrm{IV}}=\frac{q}{E I} .
$$

Let the load $q=$ const be uniformly distributed along the entire length of the beam $\left[0, L_{s}\right]$. In this case, taking into account the boundary conditions at $x=0\left(w(0)=0, w^{\prime}(0)=0\right)$, the accurate solution to Eq. (6) will be as follows:

$$
w(x)=\frac{q}{E I} \frac{x^{4}}{24}+C_{1} \frac{x^{3}}{6}+C \frac{x^{2}}{2} .
$$

The $C_{1}$ and $C_{2}$ constants can be determined based on the boundary conditions at $x=L$.

If, at $x=L_{s}$, the beam is rigidly fixed, then $w\left(L_{s}\right)=0$, $w^{\prime}(L)=0$, i.e.

$$
\begin{gathered}
\frac{q}{E I} \frac{L_{s}^{4}}{24}+C_{1} \frac{L_{s}^{3}}{6}+C_{2} \frac{L_{s}^{2}}{2}=0 . \\
\frac{q}{E I} \frac{L_{s}^{3}}{6}+C_{1} \frac{L_{s}^{2}}{2}+C_{2} L_{s}=0 .
\end{gathered}
$$

Whence it follows that:

$$
C_{1}=-\frac{q L_{s}}{2 E I}, C_{2}=\frac{q L_{s}^{2}}{12 E I}
$$

Thus, if the load $q$ is uniformly distributed along the entire length of the beam $\left[0, L_{s}\right]$, and both ends of the beam are rigidly fixed, then $w(x)$ will take the form of Eq. (7) with account for Eq. (8) and $q=1$. The bending moment $M_{x}$ and transverse force $Q_{x}$, at the unit value of the load, will take the following form:

$$
\begin{aligned}
& M_{x}=-\frac{x^{2}}{2}-E I\left(C_{1} x+C_{2}\right) ; \\
& Q_{x}=-x-E I C_{1} .
\end{aligned}
$$

Let the beam have a hinged support at $x=L_{s}$. In this case, the boundary conditions $w\left(L_{s}\right)=0, w^{\prime \prime}\left(L_{s}\right)=0$, shall apply, i.e.:

$$
\begin{gathered}
\frac{q}{E I} \frac{L_{s}^{4}}{24}+C_{1} \frac{L_{s}^{3}}{6}+C_{2} \frac{L_{s}^{2}}{2}=0 ; \\
\frac{q}{E I} \frac{L_{s}^{2}}{2}+C_{1} L_{s}+C_{2}=0 .
\end{gathered}
$$

Whence it follows that:

$$
C_{1}=-\frac{5 q L_{s}}{8 E I}, C_{2}=-\frac{q L_{s}^{2}}{8 E I} .
$$

Thus, if the load $q$ is uniformly distributed along the enitre length of the beam $[0, L]$, at $x=0$, it is fixed rigidly, and at $x=L_{s}$, it has a hinged support, then the function of deflection will take the form of Eq. (7) with account for Eq. (10) and the unit value of the load. The bending moment and transverse force at the unit value of the load will take the form of Eq. (9) at $C_{1} u$ $C_{2}$ in the form of Eq. (10).

Let the load be uniformly distributed along a part of the beam $[x 1, x 2]$. In this case, $\quad q=P \bar{\delta}\left(x-a_{1}\right)$

where $\quad \bar{\delta}\left(x-\dot{a}_{1}\right)=u\left(x-x_{1}\right)-u\left(x-x_{2}\right)$;

$u\left(x-x_{1}\right)$ and $u\left(x-x_{2}\right)$ are unit functions.

The accurate solution to Eq. (6), considering that, at $x=0$, the beam is rigidly fixed, will be as follows:

$$
\begin{gathered}
w(x)=\frac{P}{E I}\left[\frac{\left(x-x_{1}\right)^{4}}{24} u\left(x-x_{1}\right)-\frac{\left(x-x_{2}\right)^{4}}{24} u\left(x-x_{2}\right)\right]+ \\
C_{1} \frac{x^{3}}{6}+C_{2} \frac{x^{2}}{2} .
\end{gathered}
$$

Let us consider a case when, at $x=L_{S}$, the beam is rigidly fixed. In this case, the conditions $w\left(L_{s}\right)=0, w^{\prime}\left(L_{s}\right)=0$ shall apply, i.e.:

$$
\begin{aligned}
& \frac{P}{E I}\left[\frac{\left(L_{s}-x_{1}\right)^{4}}{24}-\frac{\left(L_{s}-x_{2}\right)^{4}}{24}\right]+C_{1} \frac{L_{s}^{3}}{6}+C_{2} \frac{L_{s}^{2}}{2}=0 . \\
& \frac{P}{E I}\left[\frac{\left(L_{s}-x_{1}\right)^{3}}{6}-\frac{\left(L_{s}-x_{2}\right)^{3}}{6}\right]+C_{1} \frac{L_{s}^{2}}{2}+C_{2} L_{s}=0 .
\end{aligned}
$$

Whence it follows that:

$$
\begin{gathered}
C_{1}=\frac{P}{E I L_{s}^{2}}\left[\begin{array}{l}
\frac{\left(L_{s}-x_{1}\right)^{4}}{2}-\frac{\left(L_{s}-x_{2}\right)^{4}}{2}- \\
L_{s}\left(L_{s}-x_{1}\right)^{3}+L_{s}\left(L_{s}-x_{2}\right)^{3}
\end{array}\right] ; \\
C_{2}=-\frac{P}{E I L_{s}^{2}}\left[\begin{array}{l}
\frac{\left(L_{s}-x_{1}\right)^{4}}{4}-\frac{\left(L_{s}-x_{2}\right)^{4}}{4}- \\
\frac{L_{s}}{3}\left(L_{s}-x_{1}\right)^{3}+\frac{L_{s}}{3}\left(L_{s}-x_{2}\right)^{3}
\end{array}\right] .
\end{gathered}
$$

Thus, if $q=P \bar{\delta}\left(x- \pm_{1}\right)$, and the ends of the beam are rigidly fixed, then the $w(x), M_{x}$, and $Q_{x}$ expressions, at the unit value of the load $P$ and $C_{p}, C_{2}$ in the form of Eq. (12), will be as follows: 


$$
\begin{gathered}
w(x)=\left\{\begin{array}{c}
C_{1} \frac{x^{3}}{6}+C_{2} \frac{x^{2}}{2}, \text { at } 0 \leq x \leq x_{1} ; \\
\frac{\left(x-x_{1}\right)^{4}}{24 E I}+C_{1} \frac{x^{3}}{6}+C_{2} \frac{x^{2}}{2}, \text { at } x_{1} \leq x \leq x_{2} ; \\
\frac{1}{24 E I}\left[\left(x-x_{1}\right)^{4}-\left(x-x_{2}\right)^{4}\right]+C_{1} \frac{x^{3}}{6}+C_{2} \frac{x^{2}}{2}, \text { at } x_{2} \leq x \leq L_{s},
\end{array}\right. \\
M_{x}=\left\{\begin{array}{c}
-E I\left(C_{1} x+C_{2}\right), \text { at } 0 \leq x \leq x_{1} ; \\
-\frac{\left(x-x_{1}\right)^{2}}{2}-E I\left(C_{1} x+C_{2}\right), \text { at } x_{1} \leq x \leq x_{2} ; \\
-\left[\frac{\left(x-x_{1}\right)^{2}}{2}-\frac{\left(x-x_{2}\right)^{2}}{2}\right]-E I\left(C_{1} x+C_{2}\right) \text { at } x_{2} \leq x \leq L_{s}, \\
Q_{x}=\left\{\begin{array}{c}
-E I C_{1}, \text { at } 0 \leq x \leq x_{1} ; \\
-\left(x-x_{1}\right)-E I C_{1}, \text { at } x_{1} \leq x \leq x_{2} ;
\end{array}\right.
\end{array}\right.
\end{gathered}
$$

If, at $x=L_{s}$, the beam has a hinged support, then the conditions $w\left(L_{s}\right)=0, w^{\prime \prime}\left(L_{s}\right)=0$ shall apply, i.e.:

$$
\begin{aligned}
& \frac{P}{E I}\left[\frac{\left(L_{s}-x_{1}\right)^{4}}{24}-\frac{\left(L_{s}-x_{2}\right)^{4}}{24}\right]+C_{1} \frac{L_{s}^{3}}{6}+C_{2} \frac{L_{s}^{2}}{2}=0 \\
& \frac{P}{E I}\left[\frac{\left(L_{s}-x_{1}\right)^{2}}{2}-\frac{\left(L_{s}-x_{2}\right)^{2}}{2}\right]+C_{1} L_{s}+C_{2}=0 .
\end{aligned}
$$

Whence it follows that:

$$
\begin{aligned}
& C_{1}=\frac{P}{E I L_{s}^{2}}\left[\frac{\left(L_{s}-x_{1}\right)^{4}}{8}-\frac{\left(L_{s}-x_{2}\right)^{4}}{8}-\frac{3 L_{s}^{2}}{4}\left(L_{s}-x_{1}\right)^{2}+\frac{3 L_{s}^{2}}{4}\left(L_{s}-x_{2}\right)^{2}\right] ; \\
& C_{2}=-\frac{P}{E I L_{s}^{2}}\left[\frac{\left(L_{s}-x_{1}\right)^{4}}{8}-\frac{\left(L_{s}-x_{2}\right)^{4}}{8}-\frac{L_{s}^{2}}{4}\left(L_{s}-x_{1}\right)^{2}+\frac{L_{s}^{2}}{4}\left(L_{s}-x_{2}\right)^{2}\right] .
\end{aligned}
$$

In this case, the $w(x), M_{x}$, and $Q_{x}$ expressions, at the unit value of the load $P$, will take the form of Eq. (13) with account for Eq. (14).

If the load is represented by concentrated force $F(\mathrm{kN})$, applied to point $x=a_{l}$, then

$$
\begin{aligned}
& q=F \delta\left(x-\dot{a}_{1}\right)=P \bar{\delta}\left(x-\dot{a}_{1}\right)= \\
& P\left(u\left(x-x_{1}\right)-u\left(x-x_{2}\right)\right),
\end{aligned}
$$

where $\delta\left(x-a_{1}\right)$ is a delta function; $F=P l_{1} ; l_{1}=x_{2}-x_{1}$ is some small quantity.

In this case, $w(x), M_{x}$, and $Q_{x}$ will take the form of Eq. (13) and $C_{1}, C_{2}$ in the form of Eq. (12) if both ends of the beam are rigidly fixed, or Eq. (14) if, at $x=0$, the beam is rigidly fixed, and at $x=L_{s}$, the beam has a hinged support.
When the load is represented by the moment of a couple of forces, we have the following:

$$
q=-F_{1} \delta\left(x-\alpha_{1}\right)+F_{1} \delta(x-\alpha)_{2},
$$

where $F_{l}(\mathrm{kN})$;

$$
\begin{gathered}
-F_{1} \delta\left(x-\alpha_{1}\right)=-P\left[\begin{array}{l}
u\left(x-x_{1}\right)- \\
u\left(x-x_{2}\right)
\end{array}\right] ; \\
F_{1} \delta\left(x-\alpha_{2}\right)=P\left[\begin{array}{l}
u\left(x-x_{3}\right)- \\
u\left(x-x_{4}\right)
\end{array}\right] ; \\
x_{2}-x_{1}=l_{1} ; x_{4}-x_{3}=l_{1} .
\end{gathered}
$$

In this case, considering that, at $x=0$, the beam is rigidly fixed, the accurate solution to Eq. (6) will be as follows: 


$$
w(x)=\frac{P}{E I}\left[\begin{array}{l}
\frac{\left(x-x_{1}\right)^{4}}{24} u\left(x-x_{1}\right)+ \\
\frac{\left(x-x_{2}\right)^{4}}{24} u\left(x-x_{2}\right)+ \\
\frac{\left(x-x_{3}\right)^{4}}{24} u\left(x-x_{3}\right)- \\
\frac{\left(x-x_{4}\right)^{4}}{24} u\left(x-x_{4}\right)
\end{array}\right]+C_{1} \frac{x^{3}}{6}+C_{2} \frac{x^{2}}{2} .
$$

If, at $x=L_{s}$, the beam is rigidly fixed, then $w(L)=0, w^{\prime}(L)=0$, i.e.

Whence it follows that:

$$
\begin{gathered}
P\left[\begin{array}{c}
-\frac{\left(L_{s}-x_{1}\right)^{4}}{24}+\frac{\left(L_{s}-x_{2}\right)^{4}}{24}+ \\
\frac{\left(L_{s}-x_{3}\right)^{4}}{24}-\frac{\left(L_{s}-x_{4}\right)^{4}}{24} \\
C_{1} \frac{L_{s}^{3}}{6}+C_{2} \frac{L_{s}^{2}}{2}=0 ;
\end{array}\right]+
\end{gathered}
$$

$$
\begin{gathered}
P I\left[\begin{array}{c}
-\frac{\left(L_{s}-x_{1}\right)^{3}}{6}+\frac{\left(L_{s}-x_{2}\right)^{2}}{6}+ \\
\frac{\left(L_{s}-x_{3}\right)^{3}}{6}-\frac{\left(L_{s}-x_{4}\right)^{3}}{6}
\end{array}\right]+ \\
C_{1} \frac{L_{s}^{2}}{2}+C_{2} L_{s}=0 .
\end{gathered}
$$

Thus, under the action of the unit load represented by the moment of a couple of forces and with the ends of the beam rigidly fixed, with account for Eq. (16), we obtain the following expressions for $w(x), M_{x}$, and $Q_{x}$ :

$$
\begin{aligned}
& C_{1}=\frac{P}{E I L_{S}^{2}}\left[\begin{array}{c}
-\frac{\left(L_{S}-x_{1}\right)^{4}}{2}+\frac{\left(L_{S}-x_{2}\right)^{4}}{2}+\frac{\left(L_{S}-x_{3}\right)^{4}}{2}-\frac{\left(L_{S}-x_{4}\right)^{4}}{2}+ \\
L_{S}\left(\begin{array}{l}
\left(L_{S}-x_{1}\right)^{3}-\left(L_{S}-x_{2}\right)^{3}- \\
\left(L_{S}-x_{3}\right)^{3}+\left(L_{S}-x_{4}\right)^{3}
\end{array}\right)
\end{array}\right] ; \\
& C_{2}=-\frac{P}{E I L_{S}^{2}}\left[\begin{array}{c}
-\frac{\left(L_{S}-x_{1}\right)^{4}}{4}+\frac{\left(L_{S}-x_{2}\right)^{4}}{4}+\frac{\left(L_{S}-x_{3}\right)^{4}}{4}-\frac{\left(L_{S}-x_{4}\right)^{4}}{4}+ \\
\frac{L_{S}}{3}\left(\begin{array}{l}
\left(L_{S}-x_{1}\right)^{3}-\left(L_{S}-x_{2}\right)^{3}- \\
\left(L_{S}-x_{3}\right)^{3}+\left(L_{S}-x_{4}\right)^{3}
\end{array}\right)
\end{array}\right] \text {. }
\end{aligned}
$$

$$
C_{1} \frac{x^{3}}{6}+C_{2} \frac{x^{2}}{2}, \text { at } 0 \leq x \leq x_{1} ;
$$

$$
-\frac{\left(x-x_{1}\right)^{4}}{24 E I}+C_{1} \frac{x^{3}}{6}+C_{2} \frac{x^{2}}{2}, \text { at } x_{1} \leq x \leq x_{2} \text {; }
$$

$w(x)=\left\{\frac{1}{24 E I}\left[-\left(x-x_{1}\right)^{4}+\left(x-x_{2}\right)^{4}\right]+C_{1} \frac{x^{3}}{6}+C_{2} \frac{x^{2}}{2}\right.$, at $x_{2} \leq x \leq x_{3} ;$

$\frac{1}{24 E I}\left[-\left(x-x_{1}\right)^{4}+\left(x-x_{2}\right)^{4}+\left(x-x_{3}\right)^{4}\right]+C_{1} \frac{x^{3}}{6}+C_{2} \frac{x^{2}}{2}$, at $x_{3} \leq x \leq x_{4} ;$

$\frac{1}{24 E I}\left[-\left(x-x_{1}\right)^{4}+\left(x-x_{2}\right)^{4}+\left(x-x_{3}\right)^{4}-\left(x-x_{4}\right)^{4}\right]+C_{1} \frac{x^{3}}{6}+C_{2} \frac{x^{2}}{2}$, at $x_{3} \leq x \leq L_{s}$.

$M_{x}=\left\{\begin{array}{c}-E I\left(C_{1} x+C_{2}\right), \text { at } 0 \leq x \leq x_{1} ; \\ \frac{\left(x-x_{1}\right)^{2}}{2}-E I\left(C_{1} x+C_{2}\right), \text { at } x_{1} \leq x \leq x_{2} ; \\ {\left[\frac{\left(x-x_{1}\right)^{2}}{2}-\frac{\left(x-x_{2}\right)^{2}}{2}\right]-E I\left(C_{1} x+C_{2}\right), \text { at } x_{2} \leq x \leq x_{3} ;} \\ \frac{\left(x-x_{1}\right)^{2}}{2}-\frac{\left(x-x_{2}\right)^{2}}{2}-\frac{\left(x-x_{3}\right)^{2}}{2}-E I\left(C_{1} x+C_{2}\right), \text { at } x_{3} \leq x \leq x_{4} ; \\ \frac{\left(x-x_{1}\right)^{2}}{2}-\frac{\left(x-x_{2}\right)^{2}}{2}-\frac{\left(x-x_{3}\right)^{2}}{2}+\frac{\left(x-x_{1}\right)^{2}}{2}-E I\left(C_{1} x+C_{2}\right), \text { at } x_{4} \leq x \leq L_{s} .\end{array}\right.$

$$
Q_{x}=\left\{\begin{array}{c}
-E I C_{1}, \text { at } 0 \leq x \leq x_{1} ; \\
\left(x-x_{1}\right)-E I C_{1}, \text { at } x_{1} \leq x \leq x_{2} ; \\
{\left[\left(x-x_{1}\right)-\left(x-x_{2}\right)\right]-E I C_{1}, \text { at } x_{2} \leq x \leq x_{3} ;} \\
\left(x-x_{1}\right)-\left(x-x_{2}\right)-\left(x-x_{3}\right)-E I C_{1}, \text { at } x_{3} \leq x \leq x_{4} ; \\
\left(x-x_{1}\right)-\left(x-x_{2}\right)-\left(x-x_{3}\right)+\left(x-x_{4}\right)-E I C_{1}, \text { at } x_{4} \leq x \leq L_{s} .
\end{array}\right.
$$


If, at $x=L_{s}$, the beam has a hinged support, then the conditions $w\left(L_{s}\right)=0, \quad w^{\prime \prime}\left(L_{s}\right)=0$ shall apply, i.e.:

$$
\begin{aligned}
& \frac{P}{E I}\left[-\frac{\left(L_{s}-x_{1}\right)^{4}}{24}+\frac{\left(L_{s}-x_{2}\right)^{4}}{24}+\frac{\left(L_{s}-x_{3}\right)^{4}}{24}-\frac{\left(L_{s}-x_{4}\right)^{4}}{24}\right]+C_{1} \frac{L_{s}^{3}}{6}+C_{2} \frac{L_{s}^{2}}{2}=0 \\
& \frac{P}{E I}\left[-\frac{\left(L_{s}-x_{1}\right)^{2}}{2}+\frac{\left(L_{s}-x_{2}\right)^{2}}{2}+\frac{\left(L_{s}-x_{3}\right)^{2}}{2}-\frac{\left(L_{s}-x_{4}\right)^{2}}{2}\right]+C_{1} L_{s}+C_{2}=0 .
\end{aligned}
$$

Whence it follows that:

$$
\begin{aligned}
& C_{1}=\frac{-3 P}{2 E I L_{s}^{3}}\left[\begin{array}{l}
-\frac{L_{s}^{2}\left(L_{s}-x_{1}\right)^{2}}{2}+\frac{L_{s}^{2}\left(L_{s}-x_{2}\right)^{2}}{2}+\frac{L_{s}^{2}\left(L_{s}-x_{3}\right)^{2}}{2}-\frac{L_{s}^{2}\left(L_{s}-x_{4}\right)^{2}}{2} \\
+\frac{\left(L_{s}-x_{1}\right)^{4}}{12}-\frac{\left(L_{s}-x_{2}\right)^{4}}{12}-\frac{\left(L_{s}-x_{3}\right)^{4}}{12}+\frac{\left(L_{s}-x_{4}\right)^{4}}{12}
\end{array}\right] \\
& C_{2}=-C_{1} L_{s}-\frac{P}{E I}\left[-\frac{\left(L_{s}-x_{1}\right)^{2}}{2}+\frac{\left(L_{s}-x_{2}\right)^{2}}{2}+\frac{\left(L_{s}-x_{3}\right)^{2}}{2}-\frac{\left(L_{s}-x_{4}\right)^{2}}{2}\right]
\end{aligned}
$$

In this case, $w(x), M_{x}$, and $Q_{x}$, at the unit value of the load $P$, with account for Eq. (18), will take the form of Eq. (17).

\section{Results}

Let us suppose we have a single-disc frame (Figure 1). At $l=6.0 \mathrm{~m}, F=16 \mathrm{kN}$, and $E J=$ const, it is required to determine the functions of deflection, rotation angles, and internal forces $M, Q, N$.

The frame is a statically indeterminate system. Let us determine the degree of its static indeterminacy $n_{s t}=3 \mathrm{~K}-\mathrm{H}=3 \cdot 1-2=1$, where $K$ is the number of closed circuits, $H$ is a single hinge. The frame has a rigid joint $C$ and is constrained. The degree of its kinematic indeterminacy is as follows: $n_{k}=n_{j}+n_{i}=1+0=1$, where $n_{j}$ is the number of rigid joints, $n$ is the number of linear connections. Therefore, the calculations using the force method and the calculations using the displacement method are characterized by the same labor intensity. At first, let us analyze the frame using the analytical method in the form of the force method.

Under the assumptions taken, deflection of joint $C$ of the frame is equal to zero. Therefore, by neglecting the impact of longitudinal forces on rod bending and introducing a dummy support in the cross-section $C$, we can switch from the constrained frame to a structural model in the form of a continuous beam with span $L=2 l$ (Figure $3 a$ ).

By removing the dummy support, we will replace its action on the beam with an unknown reaction $X_{1}$ and consider the obtained main system of the force method. The differential equation of the deflection curve of the beam under the action of the unknown reaction $X_{1}$ and concentrated load $F$ will be as follows:

$$
E J w^{\mathrm{IV}}(\chi)=X_{1} \delta_{x 1}-F \delta_{a 1}
$$

The required function of deflection is determined as follows:

$$
E J w(\chi)=X_{1} \psi_{1}(\chi)-F \psi_{a}(\chi)
$$

where the $\Psi_{1}(x)$ and $\Psi_{a}(x)$ functions have the following form:

$$
\begin{gathered}
\psi_{i}(x)=D_{1} \frac{x^{3}}{3 !}+D_{2} \frac{x^{2}}{2 !}+ \\
D_{3} x+D_{4}+\frac{\left(x-x_{i}\right)_{\lrcorner}^{3}}{E J 3 !} \\
\psi_{a}(x)=C_{1} \frac{x^{3}}{3 !}+C_{2} \frac{x^{2}}{2 !}+ \\
C_{3} x+C_{4}+\frac{\left(x-a_{1}\right)_{\lrcorner}^{3}}{3 !} .
\end{gathered}
$$

In what follows, the

$$
\lrcorner=\left\{\begin{array}{l}
0 \text { at } x \leq x_{i} \\
1 \text { at } x>x_{i}
\end{array}\right\}
$$

symbol denotes the spline function.

The $\Psi_{i}(x)$ function integration constants, calculated for different boundary conditions (1 - rigid support, 2 - hinged support, 3 - free edge), are given in Table 1. 
Table 1. Integration constants of the function $\Psi_{i}(x)$

\begin{tabular}{|c|c|c|c|c|c|}
\hline $\begin{array}{c}\text { Support } \\
X=0\end{array}$ & $D_{l}$ & $D_{2}$ & $D_{3}$ & $D_{4}$ & Support $x=l$ \\
\hline 1 & $-\frac{d_{i}^{2}}{l}\left(1+\frac{2 x_{i}}{l}\right)$ & $\frac{x_{i} d_{i}^{2}}{l^{2}}$ & 0 & 0 & 1 \\
\hline 1 & $\frac{3 d_{i}}{2 l}\left(1-\frac{d_{i}^{2}}{3 l^{2}}\right)$ & $\frac{d_{i}}{2}\left(\frac{d_{i}^{2}}{l^{2}}-5\right)$ & 0 & 0 & 2 \\
\hline 2 & $\frac{d_{i}^{2}}{2 l^{2}}\left(3-d_{i}\right)$ & 0 & $\frac{d_{i}^{2}}{4}\left(d_{i}-5\right)$ & 0 & 1 \\
\hline 2 & $-\frac{d_{i}}{l}$ & 0 & $\frac{d_{i} x_{i}}{6 l}\left(l+d_{i}\right)$ & 0 & 2 \\
\hline 1 & -1 & $x_{i}$ & 0 & 0 & 3 \\
\hline 3 & 0 & 0 & $-\frac{d_{i}}{2}$ & $\frac{d_{i}^{2}}{6}\left(2 l+x_{i}\right)$ & 1 \\
\hline
\end{tabular}

where $d_{1}=l-x_{i}$.

The integration constants of these functions are determined based on Table 1, following boundary conditions 2-2, corresponding to hinge fixing of the beam on supports $A$ and $B, \Psi_{1}=\Psi_{1}^{\prime \prime}=0$; $\Psi_{a}=\Psi_{a}^{\prime \prime}=0$; at $x=0$ and $x=L . D_{1}=-0,5 ; D_{2}=D_{4}=0 ; D_{3}=9$;

$$
C_{1}=-\frac{3}{4} ; \quad C_{2}=C_{4}=0 ; \quad C_{3}=\frac{63}{8} \text {. }
$$

Then, Eq. (19) takes the following form:

$$
\begin{aligned}
& \psi_{i}^{\prime}(x)=-\frac{x^{3}}{12}+9 x+\frac{(x-6)^{3}}{3 !}, \\
& \psi_{a}^{\prime}(x)=-\frac{x^{3}}{8}+\frac{63}{8} x+\frac{(x-3)^{3}}{3 !} .
\end{aligned}
$$

The unknown reaction of the dummy support $X_{1}$ can be determined based on the fact that there is no defection, $W(6)=0$, by solving the following equation: $X_{I} \Psi_{I}(6)-F \Psi_{a}(\sigma)=0$ Then:

$$
X_{1}=F \frac{\psi_{a}(6)}{\psi_{1}(6)}=16 \frac{11 \cdot 27}{12 \cdot 36}=11 \mathrm{kN}
$$

By differentiating the obtained function of deflection $w(x)$ of the dummy beam, we obtain analytical expressions for the functions of rotation angles, bending moments, and transverse forces:

$$
\begin{gathered}
E J_{\gamma}(x)=E J w^{\prime}(x)=11 \psi_{1}^{\prime}(x)-16 \psi_{a}^{\prime}(x)= \\
11\left[9-\frac{x^{2}}{4}+\frac{(x-6)_{\lrcorner}^{2}}{2}\right]-16\left[\begin{array}{l}
\frac{3}{8}\left(21-x^{2}\right)+ \\
\frac{(x-3)_{\lrcorner}^{2}}{2}
\end{array}\right] ; \\
M=-E J w^{\prime \prime}(x)=16 \psi^{\prime \prime}{ }_{a}(x)-11 \psi^{\prime \prime}{ }_{1}(x)= \\
16\left[-\frac{3}{4}-(x-3)\right\lrcorner-11\left[-\frac{x}{2}+(x-6)\right\lrcorner ; \\
Q=E J w^{\prime \prime \prime}(x)=16\left[\frac{3}{4}-U(x-3)\right]- \\
11\left[\frac{1}{2}-U(x-6)\right] .
\end{gathered}
$$

Having calculated their values in the design sections at $x=0, x=3 \pm \varepsilon, x=6 \pm \varepsilon$, and $x=12$, where $\varepsilon \rightarrow 0$, we construct $M$ and $Q$ diagrams in the continuous beam (Figures 2a, 2b), which can be transferred to the frame (Figure 3 ). The diagram of longitudinal forces $N$ is constructed based on the $Q$ diagram, assuming the equilibrium of the joint $C$. The diagrams of internal forces, obtained using the analytical method, correspond exactly to the results of the frame analysis using the classical force method and displacement method, and are represented below in Figure 3.

Due to the use of the mathematical apparatus of 


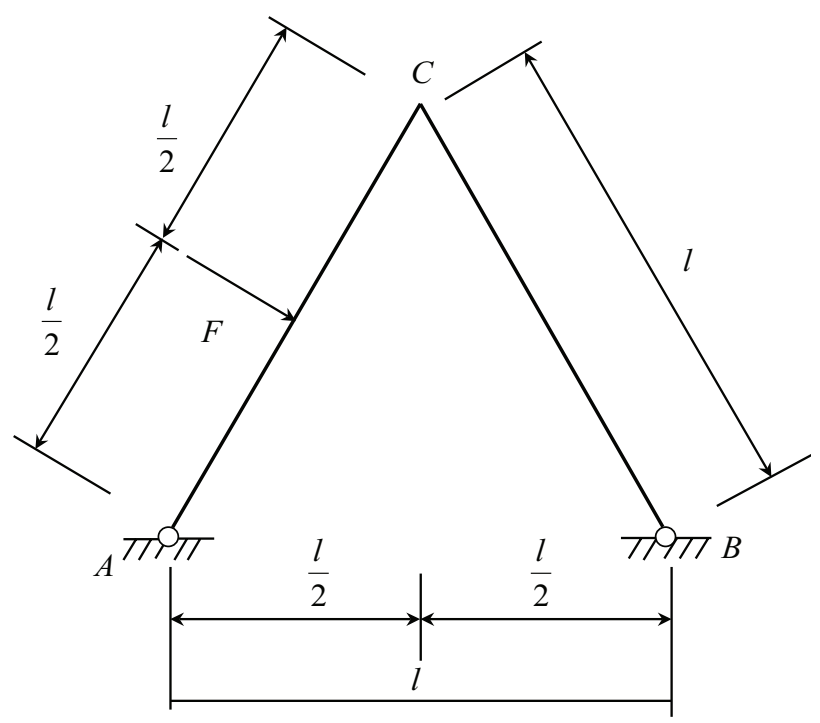

Figure 1. Single-disck frame

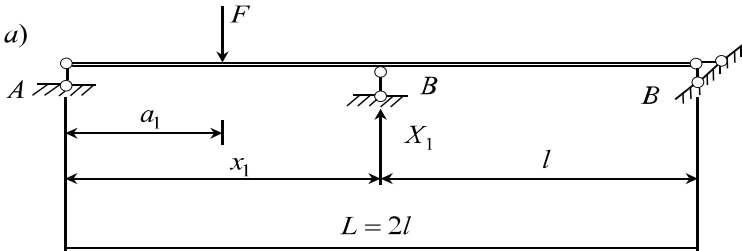

б)

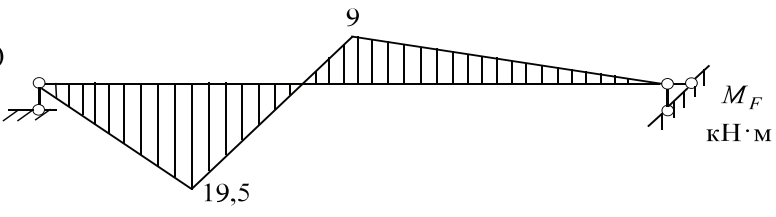

B)

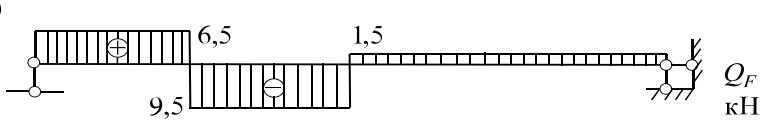

Figure 2. Structural model in the form of a continuous beam
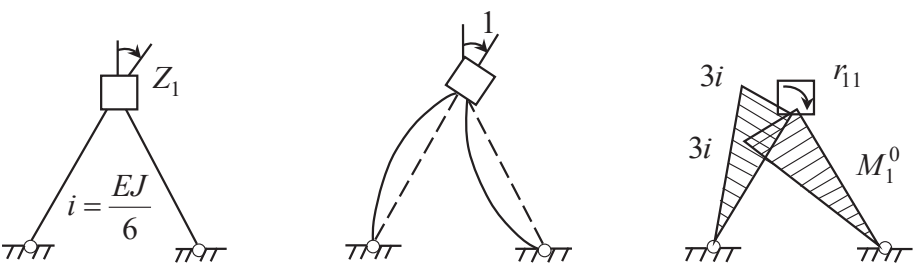

ОСMП
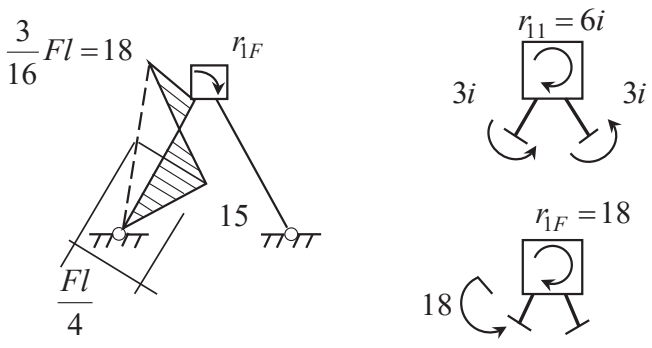

$$
\begin{aligned}
& r_{11} Z_{1}+r_{1 f}=0 \\
& 6 i Z_{1}+18=0 \\
& Z_{1}=-\frac{3}{i}(p a \partial)
\end{aligned}
$$
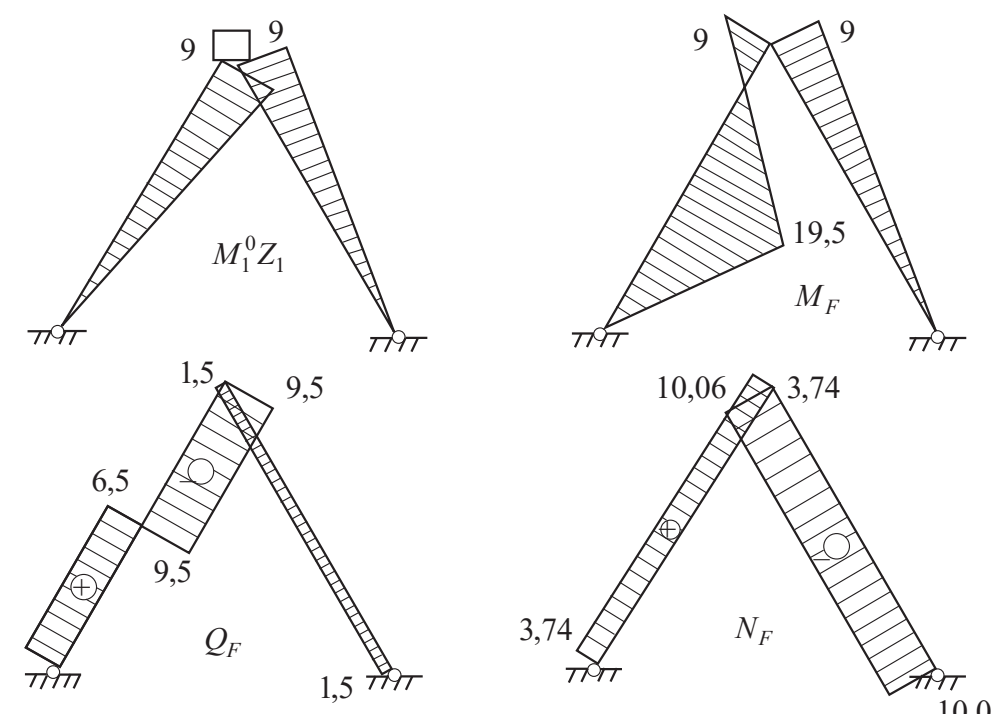

Figure 3. Diagrams of forces 
generalized functions, all expressions of the required functions of deflection $w(x)$, rotation angles $w(x)$, bending moments $M(x)$, and transverse forces $Q(x)$ ate obtained in the closed analytical form with no need to construct and multiply diagrams of bending moments by Mohr's equation in individual rods of the main system with the subsequent addition of the results.

\section{Conclusions}

For rod systems (beams, frames, trusses, combined structures), a mathematical model of deformation represents a system of linear algebraic equations, obtained based on the unified principle: in equilibrium, the sum of the works of internal forces on finite displacements in the structure is equal to the sum of the works of external forces on finite displacements. This principle makes it possible to apply the general approach to the analysis of statically indeterminate structural models, using the proposed analytical method unifying the classical displacement method, force method, and combined method on a single platform.

The proposed analytical method not only simplifies the analysis of statically indeterminate rod systems but facilitates significantly computing programming and analysis of the obtained results. 


\section{References}

Akimov, P. A. and Mozgaleva, M. L. (2014). Multi-level discrete and discrete-continuous for the local analysis of building structures. Moscow: Moscow State University of Civil Engineering, $632 \mathrm{p}$.

Alyukov, S. V. (2011). Approximation of step functions in problems of mathematical modeling. Mathematical Models and Computer Simulations, Vol. 3, Issue 5, 661. DOI: 10.1134/S2070048211050036.

Alyukov, S. V. (2012). Approximations of piecewise linear and generalized functions. Germany: LAP LAMBERT Academic Publishing, $120 \mathrm{p}$.

Babanov, V. V. (2011). Structural mechanics. In 2 volumes. Vol. 2. Moscow: Academia Publishing Center, 288 p.

Belostochny, G. N. (1999). Analytical methods for the determination of closed path integrals of singular differential equations for the thermoelastic behavior of geometrically irregular shells. Reports of Military Sciences Academy. No. 1. Volga Regional Office. Saratov, pp. 14-26.

Ignatyev, V. A. (1979). Analysis of regular statically indeterminate rod systems. Saratov: Publishing House of Saratov University, $296 \mathrm{p}$.

Ilin, V. P., Karpov, V. V. and Maslennikov, A. M. (2005). Numerical methods for solving structural mechanics problems. $2^{\text {nd }}$ edition. Moscow: ASV Publishing House, $426 \mathrm{p}$.

Karpov, V. V. (2006). Mathematical modeling, model analysis algorithms, simulation experiment in the theory of shells. Saint Petersburg: Saint Petersburg State University of Architecture and Civil Engineering, 330 p.

Karpov, V. V. (2010). Strength and stability of stiffened shells of revolution. In 2 parts. Part 1. Models and algorithms for the analysis of strength and stability of stiffened shells of revolution. Moscow: Fizmatlit, $288 \mathrm{p}$.

Karpov, V. V. (2011). Strength and stability of stiffened shells of revolution. In 2 parts. Part 2. Simulation experiment under static mechanical action. Moscow: Fizmatlit, 248 p.

Kobelev, E. A. (2018). Method of variation approximations in the theory of nonlinear deformation of irregular spatial systems. Bulletin of Civil Engineers, No, 6 (71), pp. 30-36. DOI: 10.23968/1999-5571-2018-15-6-30-36.

Kobelev, E. A. and Lukashevich, N. K. (2020a). Solving the problem of unilateral contact of the slab with the strengthening beams by the method of variational approximations. IOP Conference Series: Materials Science and Engineering, Vol. 953, 012089. DOI: $10.1088 / 1757-899 X / 953 / 1 / 012089$.

Kobelev, E. A. and Lukashevich, N. K. (2020b). Solving the contact problem when strengthening the slab with a beam using discontinuous functions. IOP Conference Series: Materials Science and Engineering, Vol. 962, 022046. DOI: 10.1088/1757-899X/962/2/022046.

Korn, G. and Korn, T. (1974). Mathematical handbook (for scientists and engineers). Moscow: Nauka, 831 p.

Korneyev, S. A. (2011). Technical rod theory. Use of generalized functions to solve problems related to the strength of materials. Omsk: Omsk State Technical University, $82 \mathrm{p}$.

Leontyev, N. N., Sobolev, D. N. and Amosov, A. A. (1996). Fundamentals of structural mechanics of rod systems. Moscow: ASV Publishing House, $541 \mathrm{p}$.

Maslennikov, A. M. (1987). Structural analysis with numerical methods. Leningrad: Publishing House of Leningrad State University, $224 \mathrm{p}$.

Maslennikov, A. M., Kobelev, E. A. and Maslennikov, N. A. (2020). Fundamentals of structural mechanics of rod systems: study guide. Saint Petersburg: Petropolis Publishing House, 342 p.

Mikhailov, B. K. (1980). Plates and shells with discontinuous parameters. Leningrad: Publishing House of Leningrad State University, $196 \mathrm{p}$.

Mikhailov, B. K., Kobelev, E. A. and Gayanov, F. F. (1990). Structural analysis with the use of generalized functions. Leningrad: Leningrad Civil Engineering and Construction Institute, 99 p.

Smirnov, V. I. (1967). A course of higher mathematics. Vol. 2. Moscow: Nauka, 655 p.

Zolotov, A. B., Akimov, P. A., Sidorov, V. N. and Mozgaleva, M. L. (2008). Mathematical methods in structural mechanics (with fundamentals of the generalized function theory). Moscow: ASV Publishing House, $336 \mathrm{p}$. 


\title{
ПРИМЕНЕНИЕ АНАЛИТИЧЕСКИХ РЕШЕНИЙ ДЛЯ ИЗГИБА БАЛОК В МЕТОДЕ ПЕРЕМЕЩЕНИЙ
}

\author{
Владимир Васильевич Карпов, Евгений Анатольевич Кобелев*, Александр Николаевич Панин \\ Санкт-Петербургский государственный архитектурно-строительный университет \\ 2-ая Красноармейская ул., 4, Санкт-Петербург, Россия \\ *E-mail: evgeny.kobelev@gmail.com
}

\begin{abstract}
Аннотация
Для расчета статически неопределимых стержневых систем обычно используют классический метод перемещений и заранее подготовленные таблицы для двух типов стержней основной системы. Математически корректное представление локальных нагрузок с помощью обобщенных функций позволяет найти точное решение дифференциального уравнения равновесия балки от воздействия произвольной поперечной нагрузки. Целью работы было получение аналитических выражений для функций прогибов, углов поворотов, поперечных усилий и изгибающих моментов от четырех видов локальных нагрузок для балок с различными краевыми условиями, чтобы затем использовать точные решения в методе перемещений. Методы: Предлагается аналитический вариант метода перемещений для расчета стержневых расчетных схем. Для балок, находящихся под действием различных видов поперечной нагрузки (равномерно-распределенной, сосредоточенной силы и пары сил), получены точные аналитические решения для функций прогибов, изгибающих моментов и поперечных сил при различных типах закрепления концов балки. Это удается сделать потому, что сосредоточенную нагрузку и нагрузку в виде момента силы можно задавать с помощью единичных столбчатых функций. Путем преобразования интегралов Мора методом интегрирования по частям показано, что система канонических уравнений метода перемещений получена на основе принципа Лагранжа. Результаты: На примере расчета статически неопределимой рамы показана эффективность предлагаемого аналитического метода по сравнению с классическим методом перемещений.
\end{abstract}

\section{Ключевые слова}

Стержневые конструкции, метод перемещений, уравнение изгиба балки, интеграл Мора, математическая модель, работа внутренних сил, работа внешних сил, принцип Лагранжа. 